\title{
Hepatitis B spliced protein (HBSP) promotes the carcinogenic effects of benzo [alpha] pyrene by interacting with microsomal epoxide hydrolase and enhancing its hydrolysis activity
}

\author{
Jin-Yan Chen ${ }^{1,2+}$, Wan-Nan Chen ${ }^{1,3+}$, Bo-Yan Jiao ${ }^{3}$, Wan-Song Lin ${ }^{3}$, Yun-Li Wu ${ }^{3}$, Ling-Ling Liư ${ }^{3}$ and Xu Lin ${ }^{1,3^{*}}$
}

\begin{abstract}
Background: The risk of hepatocellular carcinoma (HCC) increases in chronic hepatitis B surface antigen (HBsAg) carriers who often have concomitant increase in the levels of benzo[alpha]pyrene-7,8-diol-9,10-epoxide( \pm ) (BPDE)-DNA adduct in liver tissues, suggesting a possible co-carcinogenesis of Hepatitis B virus (HBV) and benzo [alpha]pyrene in HCC; however the exact mechanisms involved are unclear.
\end{abstract}

Methods: The interaction between hepatitis B spliced protein (HBSP) and microsomal epoxide hydrolase (mEH) was confirmed using GST pull-down, co-immunoprecipitation and mammalian two-hybrid assay; the effects of HBSP on mEH-mediated B[alpha]P metabolism was examined by high performance liquid chromatography (HPLC); and the influences of HBSP on B[alpha]P carcinogenicity were evaluated by bromodeoxyuridine cell proliferation, anchorage-independent growth and tumor xenograft.

Results: HBSP could interact with $\mathrm{mEH}$ in vitro and in vivo, and this interaction was mediated by the $\mathrm{N}$ terminal 47 amino acid residues of HBSP. HBSP could greatly enhance the hydrolysis activity of $\mathrm{mEH}$ in cell-free mouse liver microsomes, thus accelerating the metabolism of benzo[alpha]pyrene to produce more ultimate carcinnogen, BPDE, and this effect of HBSP requires the intact HBSP molecule. Expression of HBSP significantly increased the formation of BPDE-DNA adduct in benzo[alpha]pyrene-treated Huh-7 hepatoma cells, and this enhancement was blocked by knockdown of $\mathrm{mEH}$. HBSP could enhance the cell proliferation, accelerate the G1/S transition, and promote cell transformation and tumorigenesis of B[alpha]P-treated Huh-7 hepatoma cells.

Conclusions: Our results demonstrated that HBSP could promote carcinogenic effects of B[alpha]P by interacting with $\mathrm{mEH}$ and enhancing its hydrolysis activity.

Keywords: Hepatitis B virus, RNA splicing, Benzo[alpha]pyrene, Hepatocellular carcinoma

\section{Background}

Hepatocellular carcinoma (HCC) is the fifth most common cancer and the third leading cause of cancer death worldwide [1]. Hepatocarcinogenesis is a slow multistep and multifactorial process involving a progressive accumulation

\footnotetext{
* Correspondence: linxu@mail.fjmu.edu.cn

${ }^{\dagger}$ Equal contributors

${ }^{1}$ Key Laboratory of Ministry of Education for Gastrointestinal Cancer, Research Center of Molecular Medicine, Fujian Medical University, Fuzhou, Fujian 350004 , P.R. China

${ }^{3}$ Key Laboratory of Tumor Microbiology, Department of Medical Microbiology, Fujian Medical University, Fuzhou, Fujian 350004, P.R. China Full list of author information is available at the end of the article
}

of changes at gene and protein level [2]. Chronic hepatitis $B$ virus (HBV) infection is a major risk factor for $\mathrm{HCC}$ in the endemic areas. Several lines of evidences suggested that a synergistic interaction between environmental carcinogens and HBV-carcinogens may play a critical role in the carcinogenesis of HCC [3,4].

HBV is a small enveloped hepatotropic virus with a partially double-stranded DNA genome of approximately $3.2 \mathrm{~kb}$ in length [5]. In addition to the immune response to the viral proteins, which is considered to play a major role in the liver disease outcome, some HBV proteins also directly participate in chronic hepatitis and HCC, among

\section{Biomed Central}


which transcription activators of $\mathrm{X}$ protein $(\mathrm{HBx})[6,7]$ and truncated middle surface protein (MHBst) have been extensively studied [8]. In the past decade, a novel hepatitis B spliced protein (HBSP) encoded by a $2.2 \mathrm{~kb}$ singly spliced defective HBV genome (spliced between positions $2447 \mathrm{nt}$ and $489 \mathrm{nt}$ ) has been detected in the liver tissues and the serum from patients with hepatitis B $[9,10]$. HBSP has been shown to play an important role in hepatopathogenesis [11-13], yet the exact mechanisms remain to be fully elucidated.

Polycyclic aromatic hydrocarbons (PAHs) are ubiquitous environmental pollutants [3], exposure to which causes many cancers mostly mediating through the PAHs' reactive metabolites, dihydrodiol epoxides [14]. Benzo[ $\alpha]$ pyrene $(\mathrm{B}[\mathrm{alpha}] \mathrm{P})$ is a best characterized $\mathrm{PAH}$ compound and is considered to be an indirect genotoxin. Its carcinogenic and mutagenic effects are manifested after being converted in vivo into a vicinal $\mathrm{B}$ [alpha]P-7,8-diol-9,10-epoxide (BPDE) $[15,16]$. In male infant mice, exposure to $B$ [alpha]P induces liver tumors [17]. In addition, epidemicological studies have shown that the risk for developing HCC increased dramatically in those with the combination of higher BPDE-DNA adducts and HBV infection $[3,4]$, suggesting the possible role of HBV-B[alpha]P interaction in hepatocarcinogenesis.

Microsomal epoxide hydrolase $(\mathrm{mEH})$ plays a pivotal role in $\mathrm{B}[$ alpha]P conversion by hydration of $\mathrm{B}$ [alpha]P-7,8oxide to $\mathrm{B}$ [alpha]P-7,8-diol, an important intermediate molecule of B[alpha]P metabolism $[18,19]$. The critical role of $\mathrm{mEH}$ bioactivation in $\mathrm{PAH}$-induced carcinogenesis was demonstrated in EPHX1 (coding for $\mathrm{mEH}$ ) null mice which were completely resistant to the tumorigenic effects of dimethylbenz[alpha]anthracene in a complete carcinogenesis assay [20]. In our previous study by a yeast two-hybrid screening [21], $\mathrm{mEH}$ was identified as a specific binding partner for HBSP from a human liver cDNA library. In this study, complex formation between HBSP and $\mathrm{mEH}$ under both cell-free and intracellular conditions was further confirmed, and the effects of HBSP on mEH-mediated B [alpha]P metabolism and the carcinogenic effects of $\mathrm{B}$ [alpha]P were evaluated. The results demonstrated that HBSP could promote carcinogenic effects of B[alpha]P by interacting with $\mathrm{mEH}$ and enhancing its hydrolysis activity.

\section{Methods}

\section{Plasmid constructs}

Vector pCMVTNT-EPHX1 used for in vitro translation of microsomal epoxide hydrolase $(\mathrm{mEH})$ was constructed by inserting of EPHX1 gene (GeneBank Accession No. NM_000120) cDNA into pCMVTNT (Promega, Madison, WI, USA) between the Xho I and Kpn I sites, EPHX1 gene cDNA was amplified by reverse transcription polymerase chain reaction (RT-PCR) from the total RNA isolated from Huh-7 hepatoma cells. The primers used were: forward primer, 5' - CCGCTCGAGGCCACCATGTGGCTA
GAAATCCTCCTCACT-3'; reverse primer, 5'-CGGGG TACCTCATTGCCGCTCCAGCAC-3'. pACT-EPHX1 ${ }_{353-455}$ coding for 353-455 amino acids of $\mathrm{mEH}$ was generated by an in-frame insertion of PCR amplified fragment using screened cDNA library prey plasmid as a template into pACT between the Sal I and Not I sites (encodes a herpes simplex virus type 1 VP16 protein, Promega). The primers used were: forward primer: 5 '-ACGCGTCGACT TGACCTGCTGACCAAC-3'; reverse primer: 5' -ATAAG AATGCGGCCGC TCATTGCCGCTCCAGCAC-3'. pGEXHBSP coding for GST-HBSP protein, pBIND-HBSP, pBIND-HBSP1-47 and pBIND-HBSP48-111, which respectively codes for GAL4 DNA-binding domain fused full length, $\mathrm{N}$ terminal 47 amino acids and $\mathrm{C}$ terminal 64 amino acids of HBSP, were described previously [21].

\section{GST pull-down assay}

E. coli Rosetta (DE3) (Novagen, Madison, Wisconsin, USA) was transformed with pGEX-HBSP, and the expression of GST-fused HBSP was induced with $0.5 \mathrm{mM}$ isopropy l$\beta$-D-thiogalactopyranoside (IPTG, Merck, Darmstadt, Germany) for $3 \mathrm{~h}$ at $28^{\circ} \mathrm{C}$. The cells were harvested and suspended in phosphatate-buffered saline (PBS) containing $5 \mathrm{mM}$ DTT and protease inhibitor cocktail (Roche Diagnostics, Mannheim, Germany). The cells were then disrupted by sonication. After centrifugation, the glutathioneSepharose 4B beads (GE Healthcare, Uppsala, Sweden) were added to the supernatants and incubated overnight at $4^{\circ} \mathrm{C}$. Then the glutathione-Sepharose $4 \mathrm{~B}$ beads were washed three times with PBS containing $5 \mathrm{mM}$ DTT and protease inhibitor cocktail (Calbiochem, La Jolla, CA). ${ }^{35} \mathrm{~S}$-Labeled $\mathrm{mEH}$ protein was prepared using the TNT T7 Coupled Reticulocyte Lysate System (Promega) by adding $2 \mu \mathrm{g}$ of pCMVTNT-EPHX1 and $50 \mu \mathrm{Ci}$ of ${ }^{35} \mathrm{~S}$-methionine (Amersham Pharmacia Biotech, Piscataway, NJ, USA). For GST pull-down assay, ${ }^{35}$ S-labeled $\mathrm{mEH}$ was added to the GST recombinant proteins and glutathioneSepharose $4 \mathrm{~B}$ beads, and incubated overnight at $4^{\circ} \mathrm{C}$. Beads were washed three times with $1 \%$ Triton X-100 in PBS, re-suspended and subjected to $12 \%$ sodium dodecyl sulphate-polyacrylamide gel electrophoresis (SDS-PAGE). The presence of ${ }^{35} \mathrm{~S}-\mathrm{mEH}$ was detected by autoradiography.

\section{Co-immunoprecipitation (Co-IP) assay}

A total of $4 \times 10^{6}$ Huh-7 hepatoma cells in a $10 \mathrm{~cm}$ dish were transfected with $12 \mu \mathrm{g}$ each of the constructs pBIND-HBSP, pBIND-HBSP ${ }_{1-47}$, pBIND-HBSP $_{48-111}$ or pBIND. Forty-eight hours after transfection, the cells were washed three times with PBS and lysed using RIPA lysis buffer (Pierce, Rockford, IL, USA) containing a proteinase inhibitor cocktail (Roche Diagnsotics). The soluble proteins were pre-cleared with $100 \mu \mathrm{L}$ of a $50 \%$ slurry of protein A agarose (Invitrogen, Carlsbad, CA, USA), and then the clear lysates were mixed with $2 \mu \mathrm{g}$ 
of goat polyclonal anti-mEH IgG (Santa Cruz Biotechnology, Santa Cruz, CA, USA) and $100 \mu \mathrm{L}$ of a $50 \%$ slurry of protein A agarose. The immunoprecipitated complexes were washed with lysis buffer and then analyzed by $12 \%$ SDS-PAGE and western blot, using specific antibodies including anti-GAL4BD monoclonal antibody (1:4000 dilution, Clontech, Palo Alto, CA, USA) and anti-mEH antibody (1:200 dilution, Santa Cruz Boitechnology).

\section{Mammalian two-hybrid assay}

CheckMate Mammalian Two-Hybrid System (Promega) was used following the manufacturer's instructions. Briefly, Huh-7 hepatoma cells $\left(10^{6}\right.$ cells per $6 \mathrm{~cm}$ dish) were cotransfected with pACT-EPHX1 ${ }_{353-455}$ and pBIND-HBSP, pBIND-HBSP $_{1-47}$ or pBIND-HBSP ${ }_{48-111}$ vector with the pG5luc as a reporter plasmid, using Lipofectamine 2000 (Invitrogen) according to the manufacturer's instructions. Paired empty plasmids pBIND and pACT were used as negative controls. At $48 \mathrm{~h}$ post-transfection, the cells were harvested and renilla-normalized firefly luciferase activities were measured using the Dual-Luciferase Reporter Assay System (Promega) following the manufacturer's instructions. The relative luciferase activities were obtained by comparison to the negative controls (pBIND and pACT), which were set to 1 in each experiment. Each transfection was performed three times, and each time in duplicate. The relative luciferase activities are presented as mean \pm SD.

\section{Recombinant adenoviruses preparation}

Recombinant adenoviruses were generated by using AdEasy XL System (Stratagene, La Jolla, CA, USA) following the manufacturer's instruction. Briefly, plasmid pShuttle-IRES-hrGFP-1-HBSP was generated by inserting HBSP gene into the vector pShuttle-IRES-hrGFP-1. HBSP-expressing (pAdHBSP) or control (pAdControl) recombinant adenoviral vectors were then generated by homologous recombination of pAdEasy- 1 and pShuttleIRES-hrGFP-1-HBSP or pShuttle-IRES-hrGFP-1 in E. coli BJ5183-AD-1. The colonies obtained were screened for appropriate recombination events by Pac I restriction endonuclease analyses. The pAdHBSP and pAdControl were then digested with Pme I and used to transfect the 293A packaging cell line (Invitrogen) to produce HBSP-expressing (HBSP-Ad) and control (GFP-Ad) recombinant adenoviruses. Exponentially growing Huh-7 hepatoma cells were infected with these recombinant adenoviruses at a multiplicity of infection (MOI) of 100. This dose of virus was sufficient to give $100 \%$ infectivity as determined by GFP expression under fluorescence microscopy.

Analysis of effects of HBSP on styrene oxide (STO) hydrolysis $4 \mu \mathrm{g}$ of mouse liver microsomal protein (Sigma, St. Louis, MO, USA) was incubated with 40 or $100 \mu \mathrm{g}$ of bacterially expressed NUS-StrepII-tagged HBSP, $\mathrm{HBSP}_{1-47}$ (N terminal 47 amino acids of HBSP), $\mathrm{HBSP}_{48-111}$ (C terminal 64 amino acids of HBSP) or Nus-StrepII (negative control) [21] for $20 \mathrm{~min}$ at $37^{\circ} \mathrm{C}$. After incubation, the reaction was initiated by adding $400 \mu \mathrm{L}$ of $0.1 \mathrm{M}$ potassium phosphate buffer (pH7.4) and $1 \mathrm{mM}$ of STO (Sigma). Then the mixture was incubated for $20 \mathrm{~min}$ at $37^{\circ} \mathrm{C}$. The reaction was terminated by adding $1 \mathrm{~mL}$ of cold ethyl acetate. The mixtures were measured by high performance liquid chromatography (HPLC) as described before [22]. The STO was identified by comparison of their retention times with co-injected authentic standards of STO, and quantified by integrating the areas under the peaks. The assay was performed three times, and the results were expressed as mean $\pm \mathrm{SD}$.

\section{Analysis of effects of HBSP on B[alpha]P metabolism}

$4 \mu \mathrm{g}$ of mouse liver microsomal protein was incubated with 40 or $100 \mu \mathrm{g}$ of StrepII-tagged HBSP, $\mathrm{HBSP}_{1-47}, \mathrm{HBSP}_{48-111}$ or NUS-StrepII (negative control) for $20 \mathrm{~min}$ at $37^{\circ} \mathrm{C}$. After incubation, the reaction was initiated by adding $200 \mu \mathrm{L}$ of $0.1 \mathrm{M}$ potassium phosphate buffer (pH7.4), $10 \mu \mathrm{M}$ NADPH (Sigma) and $0.5 \mu \mathrm{M}$ of B[alpha]P (Sigma). Then the mixtures were incubated for $20 \mathrm{~min}$ at $37^{\circ} \mathrm{C}$. The reaction was terminated by adding $1 \mathrm{~mL}$ of cold ethyl acetate. The mixtures were measured by HPLC as previously described [23]. The B[alpha]P metabolites were identified by comparing their retention times with co-injected authentic standards of B[alpha]P and B[alpha]P-7,8-diol-9,10epoxide (BPDE) and were quantified by integrating the areas under the peaks. $\mathrm{B}$ [alpha]P overall metablic turnover was expressed as percentage of initial substrate concentration. The analyses were performed three times, and the results were expressed as mean $\pm \mathrm{SD}$.

\section{Cell culture and B[alpha]P exposure}

Huh-7 hepatoma cells were cultured in Dulbecco's modified Eagle's medium (DMEM, Invitrogen) supplemented with $10 \%$ fetal bovine serum (FBS, Invitrogen). $5 \times 10^{5}$ Huh-7 hepatoma cells were infected with 100 MOI of recombinant adenoviruses GFP-Ad and HBSP-Ad, respectively. 72 hours after the infection, the cells were treated with $1 \mu \mathrm{M}$ of $\mathrm{B}$ [alpha]P for $24 \mathrm{~h}$, and used for detection of cellular BPDE-DNA by immunocytochemistry. Cells used for assay of proliferation, cell cycle, transformation and tumorigenicity were prepared by viral infection and continuously treated with $1 \mu \mathrm{M}$ of $\mathrm{B}$ [alpha]P for 4 weeks (10 passages), then the cells were harvested and kept at $-80^{\circ} \mathrm{C}$ until use. These cells were designated as Huh-7/HBSP/B[alpha] $\mathrm{P}$ (Huh-7 hepatoma cells infected with HBSP-Ad and treated with $\mathrm{B}[$ alpha]P), Huh-7/GFP/B[alpha]P (Huh-7 hepatoma cells infected with GFP-Ad and treated with B[alpha]P), Huh-7/HBSP (Huh-7 hepatoma cells infected with HBSPAd and without treating by $\mathrm{B}[\mathrm{alpha}] \mathrm{P})$ or Huh-7/GFP 
(Huh-7 hepatoma cells infected with GFP-Ad and without treating by $\mathrm{B}[$ alpha $] \mathrm{P})$.

\section{RNA interference assay}

100 pmol of either small interfering RNA targeting $\mathrm{mEH}$ (mEH siRNA, Santa Cruz Biotechnology) or negative control was used for transfection by lipofectamine RNAiMAX reagent (Invitrogen) in accordance with the manufacturer's instructions. The cells were collected using RIPA lysis buffer (Pierce) $48 \mathrm{~h}$ after transfection. The protein concentration was measured with a BCA Protein Quant Kit (Bio-Rad, Hercules, CA, USA).

\section{Western blotting analysis}

A total of $30 \mu \mathrm{g}$ protein was subjected to $12 \%$ SDSPAGE, and then electrophoretically transferred to a polyvinylidene fluoride (PVDF) membrane (Millipore, Billerica, MA, USA). Protein blots were incubated separately with a panel of specific antibodies such as anti-mEH (1:500 dilution, Santa Cruz Biotechnology) and anti- $\beta$-actin (1:4000 dilution, Sigma). An alkaline phosphatase (AP)conjugated goat anti-mouse IgG was used as a secondary antibody. CDP-Star reagent (Roche Diagnostics) was used for color development.

\section{Immunocytochemistry assay of BPDE-DNA}

The procedure was performed as previously described [24]. Briefly, when the cells on sterilized glass coverslips reached $70-80 \%$ confluence, they were fixed with $4 \%$ paraformaldehyde in PBS, and permeabilized with $0.2 \%$ Triton X-100 in PBS. After incubation with anti-BPDE-DNA (1:50 dilution, Santa Cruz), the cells were incubated with a biotinylated secondary antibody followed by streptavidin conjugated with horseradish peroxidase (HRP) for $10 \mathrm{~min}$. The immunoreaction was visualized using 3-3' diaminobenzidine tetrachloride (DAB, Santa Cruz). The slides were mounted with Eukitt (Sigma) and observed with an Olympus BX60 microscope. Images were captured with Image-Pro Express 6.0 (IPE6.0) software.

\section{Bromodeoxyuridine cell proliferation assay}

Huh-7/HBSP/B[alpha]P, Huh-7/GFP/B[alpha]P, Huh-7/ HBSP or Huh-7/GFP were seeded triplicate in 96-well plates at $2 \times 10^{3} /$ well. Cell proliferation was determined daily for 9 days by bromodeoxyuridine (BrDU) assay according to the manufacturer's instructions. Briefly, after the cells were plated and serum-starved for 24 hours, BrDU was added to each well at a dilution of 1:2000 and the cells incubated for an additional $24 \mathrm{~h}$. The BrDU incorporation (a measure of DNA synthesis and growth) was measured by using the BrDU Cell Proliferation assay kit (CalBiochem, San Diego, CA, USA) at $450 \mathrm{~nm}$ using a microplate reader. The assay was performed three times, and the results were expressed as mean \pm SD.

\section{Cell cycle analysis}

Huh-7/HBSP/B[alpha]P or Huh-7/GFP/B[alpha]P were seeded in 6-well plates at $1 \times 10^{4} /$ well and serum-starved with $0.5 \%$ FBS DMEM for $24 \mathrm{~h}$. Cells were harvested after serum starvation at day 2, 4, and 6 days. Cells were fixed with ice-cold $70 \%$ ethanol (pre-chilled at $-20^{\circ} \mathrm{C}$ ), washed with PBS ( $\mathrm{pH} 7.2$ ), incubated with $0.05 \mathrm{mg} / \mathrm{mL}$ propidium iodide (PI, Sigma) and $1 \mu \mathrm{g} / \mathrm{mL}$ RNase A at $37^{\circ} \mathrm{C}$ for $30 \mathrm{~min}$ in dark. The DNA content of 10,000 cells was analyzed by flow cytometry (Beckman Coulter, Miami, Florida, USA) and CXP 2.2. software. The percentage of each phase of the cell cycle was determined.

\section{Anchorage-independent growth in soft agar}

The assay was performed as previously described [25]. Briefly, $2 \times 10^{3}$ Huh-7/HBSP/B[alpha]P or Huh-7/GFP/B [alpha]P were suspended in $0.3 \%$ agarose in DMEM supplemented with 10\% FBS, and plated in $60 \mathrm{~mm}$ dishes over a basal layer of $0.6 \%$ agarose in the same medium. All dishes were incubated at $37^{\circ} \mathrm{C}$ in a $5 \% \mathrm{CO}_{2}$ humidified atmosphere, and were examined microscopically for colony formation after a 2-week incubation.

\section{Tumor xerograft}

All the procedures involving animals were approved by Experimental Animal Ethics Committee, Fujian Medical University. The method was used as previously described [26] with minor changes. Briefly, the right flanks of BALB/C nude mice (nu/nu) (male, 4 weeks old) were inoculated subcutaneously with pooled $2 \times 10^{6}$ of $\mathrm{Huh}-7 / \mathrm{HBSP} / \mathrm{B}$ [alpha]P or Huh-7/GFP/B[alpha]P in $0.2 \mathrm{~mL}$ PBS per animal. Tumor size was measured every 3 days, and the tumor volume was calculated by using the following formula: $\left(\right.$ length $\times$ width $\left.^{2}\right) / 2$. After 21 days of inoculation, all mice were sacrificed, tumors were dissected out, weighted, and processed for immunohistochemistry.

\section{Immunohistochemistry}

Tissues were fixed in $4 \%$ neutral buffered formalin, processed, then embedded in paraffin and cut into $5 \mu \mathrm{m} \mathrm{sec}-$ tions. Tissues sections were deparaffinized and rehydrated. Endogenous peroxidase were blocked with $10 \mathrm{~min}$ incubation in $3 \% \mathrm{H}_{2} \mathrm{O}_{2}$ in PBS. After blocking of non-specific sites with $1.5 \%$ blocking serum in PBS for $1 \mathrm{~h}$ at room temperature (RT), tissue sections were incubated $1 \mathrm{~h}$ at RT with the anti-BPDE-DNA. After a 30 min reaction with a biotinylated secondary antibody, slides were washed with PBS and incubated with streptavidin conjugated with HRP for $10 \mathrm{~min}$. The reaction was then revealed with DAB. Then the slides were mounted with Eukitt and observed with an Olympus BX60 microscope. Images were captured with IPE6.0 software. 


\section{Availability of supporting data}

The data sets supporting the results of this article are available in the Addgene plasmid repository, IDs 53113 and 53114, http://www.addgene.org/depositing/70984/

\section{Results}

In vitro and In vivo interaction between HBSP and $\mathrm{mEH}$

A GST pull-down assay was performed to confirm the direct interaction between recombinant HBSP and recombinant $\mathrm{mEH}$ in vitro. The result showed that the recombinant GST fusion proteins were well expressed and precipitated by glutathione-Sepharose $4 \mathrm{~B}$ beads (Figure 1A). GST-HBSP fusion protein complexed with ${ }^{35}$ S-labeled $\mathrm{mEH}$ (Figure 1B).

Co-immunoprecipitation (Co-IP) assays were performed to examine the intracellular complex formation between recombinant HBSP and endogenous $\mathrm{mEH}$. As shown in Figure $1 \mathrm{C}$, endogenous $\mathrm{mEH}$ in Huh-7 hepatoma cells efficiently co-immunoprecipitated with full-length HBSP and $\mathrm{HBSP}_{1-47}$, but not $\mathrm{HBSP}_{48-111}$ or GAL4BD, indicating that the $\mathrm{mEH}$-binding site of HBSP is located within the $\mathrm{N}$-terminal half of the molecule (residues 1-47).

A mammalian two-hybrid system was further employed to enable an intracellular evaluation of the binding between HBSP and $\mathrm{mEH}$ in Huh-7 hepatoma cells. The results demonstrated that GAL4BD-tagged HBSP, $\mathrm{HBSP}_{1-47}$ and HBSP $_{48-111}$ as well as VP16-tagged $\mathrm{mEH}_{353-455}$ expressed well in transfected Huh-7 hepatoma cells (Figure 1D). The luciferase activities (Figure 1E) of Huh-7 hepatoma cells cotransfected with pACT-mEH ${ }_{353-455}$ and pBIND-HBSP or pBIND-HBSP $_{1-47}$ were significantly higher $(\sim 9$ fold for pBIND-HBSP and $\sim 12$ fold for pBIND-HBSP ${ }_{1-47}$ ) as compared to the negative control $(\mathrm{P}<0.01)$, while the luciferase activity for the pBIND-HBSP ${ }_{48-111}$ group was similar to negative control. The results indicate that HBSP-mEH binding interaction can be detected within mammalian cells and that the $\mathrm{mEH}$-binding site of HBSP molecule is again localized to the $\mathrm{N}$-terminal half.

\section{HBSP enhances the hydrolysis activity of $\mathrm{mEH}$}

Hydrolysis of the styrene oxide (STO) to styrene glycol was widely used to evaluate specifically the hydrolysis activity of $\mathrm{mEH}$ in cell free mouse liver microsomes [16]. The results (Figure 2A) showed that hydrolysis of the STO by mouse liver microsomes in the presence of $40 \mu \mathrm{g}$ and $100 \mu \mathrm{g}$ HBSP was faster than that in NUS-StrepII (negative control) $(105.13 \pm 5.62$ vs $79.56 \pm 4.72$ and $134.52 \pm 1.66$ vs $89.33 \pm 13.62$, respectively, $\mathrm{P}<0.05)$. In contrast, as for $\mathrm{HBSP}_{1-47}$ and $\mathrm{HBSP}_{48-111}$, no significant differences were observed $(\mathrm{P}>0.05)$. These observations suggest that HBSP can enhance the hydrolysis activity of $\mathrm{mEH}$, and this effect is dependent on HBSP integrity since neither $\mathrm{HBSP}_{1-47}$ nor $\mathrm{HBSP}_{48-111}$ was functional.
The influence of HBSP on the metabolism of B[alpha]P in cell-free mouse liver microsomes was also measured. The results demonstrated that the overall turnover of $\mathrm{B}$ [alpha]P (expressed as\% initial substrate concentration) (Figure 2B) in the presence of $40 \mu \mathrm{g}$ or $100 \mu \mathrm{g}$ of HBSP was higher than that of NUS-StrepII $(58.65 \pm 1.92$ vs $43.49 \pm 4.78$ and $64.48 \pm 1.78$ vs $48.56 \pm 1.0$, respectively, $\mathrm{P}<0.05$ ). In addition, substantially more BPDE (Figure $2 \mathrm{C}$ ), was formed in the presence of $40 \mu \mathrm{g}$ or $100 \mu \mathrm{g}$ of HBSP as compared to the negative control $(2.79 \pm 0.58$ vs $1.79 \pm$ 0.24 and $3.65 \pm 0.52$ vs $1.65 \pm 0.47$, respectively, $\mathrm{P}<0.05$ ). These results indicated that HBSP could enhance the metabolism of $\mathrm{B}$ [alpha]P in cell-free mouse liver microsomes.

The influence of HBSP on B[alpha]P metabolism in living cells was further investigated. As shown in Figure 2D, the Huh-7 hepatoma cells infected with HBSP-Ad exhibited more intense immunostains than control cells, indicative of higher amount of BPDE-DNA adducts within the nuclei. In addition, when $\mathrm{mEH}$ in HBSP-Ad infected cells was knocked down by specific siRNA (Figure 2E), the staining intensity was reverted back to the level similar to the negative control (Figure 2F). These results indicated that HBSP accelerated the metabolism of Benzo[alpha]pyrene through interaction with $\mathrm{mEH}$ in Huh-7 hepatoma cells.

\section{HBSP enhances the proliferation of B[alpha]P-treated Huh-7 hepatoma cells}

As shown in Figure $3 \mathrm{~A}$ and $\mathrm{B}$, Huh-7/HBSP/B[alpha]P and Huh-7/HBSP could express HBSP and Huh-7/HBSP/ $\mathrm{B}$ [alpha]P showed a more intense immunoreactivity for anti-BPDE-DNA antibody than Huh-7/GFP/B[alpha]P. In order to investigate the effects of HBSP on the proliferation of $\mathrm{B}$ [alpha]P-treated cells, Huh-7/HBSP/B[alpha]P, Huh-7/GFP/B[alpha]P or Huh-7/HBSP cells were seeded and cultured, BrdU assay was performed. The results demonstrated that the proliferation of Huh-7/HBSP/B[alpha]P increased from day 4 to day 7 , and significantly faster than that of Huh-7/GFP/B[alpha]P, Huh-7/HBSP or Huh-7/GFP (Figure 3C). These results indicated that HBSP could enhance the proliferation of $\mathrm{B}$ [alpha]P-treated Huh-7 hepatoma cells and that this enhancement is not the result of HBSP alone directly acting upon Huh-7 but requires the presence of $\mathrm{B}[\mathrm{alpha}] \mathrm{P}$.

\section{HBSP induces cell cycle alterations of B[alpha]P-treated Huh-7 hepatoma cells}

It has been reported that the observed increase in the proliferation of cells treated with $\mathrm{B}[\mathrm{alpha}] \mathrm{P}$ was accompanied by an increased G1/S transition $[27,28]$. To investigate the effects of HBSP on the cell cycle in B[alpha]P-treated cells, cell cycle phase distributions of Huh-7/HBSP/B[alpha]P and Huh-7/GFP/B[alpha]P were compared at day 2, 4, and 6 after serum starvation. The results showed that 


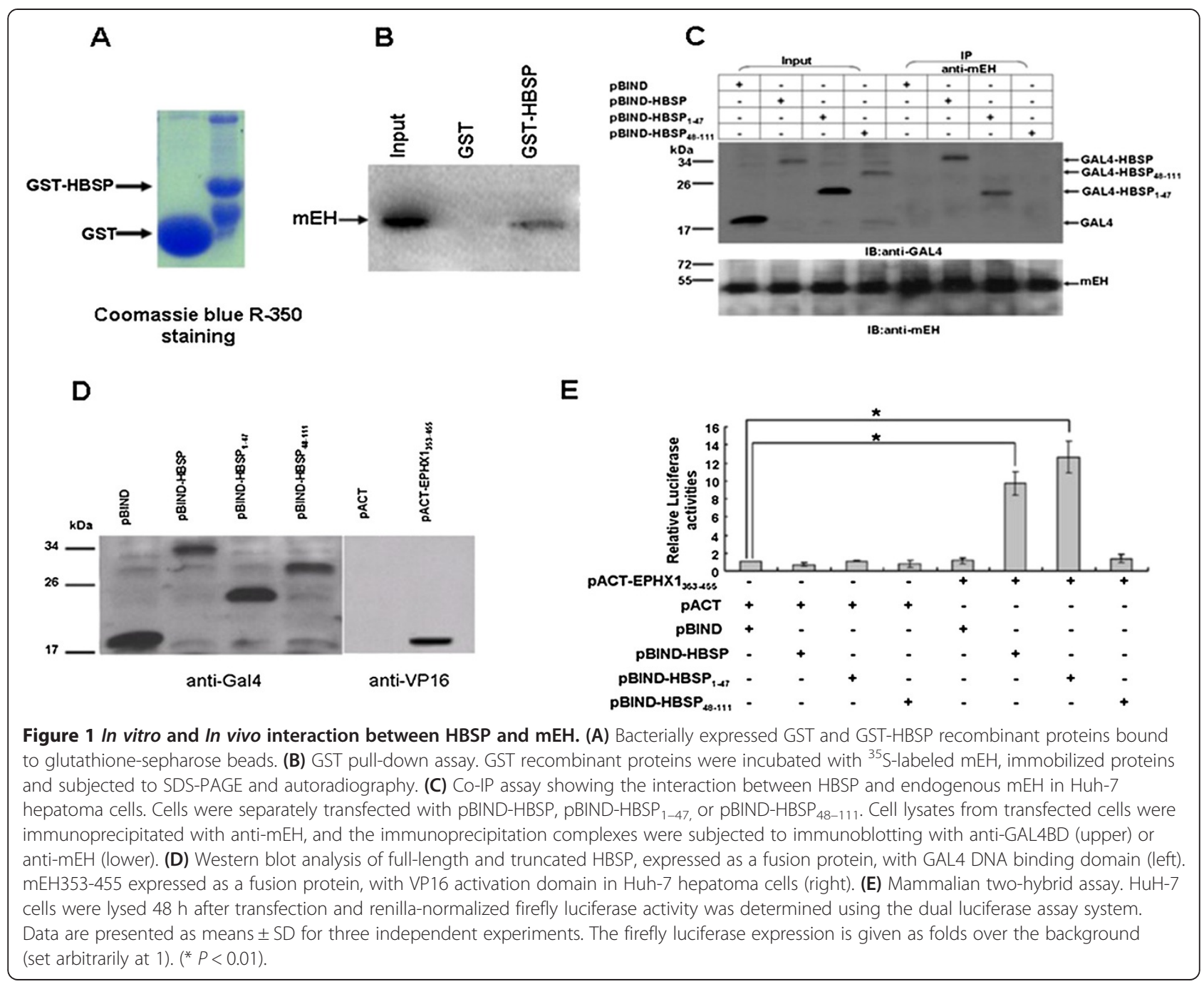

Huh-7/HBSP/B[alpha]P displayed a dramatic alteration in cell cycle phase distribution with a decrease in the fraction of the cells in G1 phase and a corresponding increase in the fraction of the cells in S phase (Figure 4). The percentage of $\mathrm{S}$ phase in Huh-7/HBSP/B[alpha]P was $45.99 \%, 57.95 \%$ and $58.14 \%$ for 2,4 and 6 day, respectively, significantly higher than those of Huh-7/GFP/B[alpha]P $(37.74 \%, 42.94 \%$ and $48.95 \%$, respectively). These data showed that HBSP increased G1/S transition of B[alpha] P-treated Huh-7 hepatoma cells.

\section{HBSP enhances anchorage-independent growth of B [alpha]P-treated Huh-7 hepatoma cells in soft agar}

To investigate whether HBSP affects the transformation of B[alpha]P-treated Huh-7 cells, the anchorage-independent growth in soft agar was performed. The results revealed that Huh-7/HBSP/B[alpha]P grew significantly better than the control of Huh-7/GFP/B[alpha]P in soft agar (Figure 5A). Moreover, Huh-7/HBSP/B[alpha]P cells showed a dramatic increase in the number of the colonies in soft agar than Huh-7/GFP/ B[alpha]P (Figure 5B). These data indicate that HBSP enhances malignant transformation of $\mathrm{B}[\mathrm{alpha}] \mathrm{P}$ treated Huh-7 hepatoma cells.

\section{HBSP enhances tumor development of B[alpha]P-treated} Huh-7 hepatoma cells in nude mice

To test the effect of HBSP on tumorigenicity of B[alpha] P-treated Huh-7 cells, nude mice were inoculated with Huh-7/HBSP/B[alpha]P or Huh-7/GFP/B[alpha]P. All of the mice inoculated with the Huh-7/HBSP/B[alpha]P developed visible tumors within 9 days after the injection, while only six of eight (75\%) mice inoculated with Huh7/GFP/B[alpha]P developed visible tumors on day 15 post-injection. After the mice were sacrificed on day 21 post inoculation (Figure 6A), the xenografts were dissected out (Figure $6 \mathrm{~B}$ ). The volume and weight of the xenografts were measured, and the presence of BPDE-DNA in the xenografts was detected. The results demonstrated 


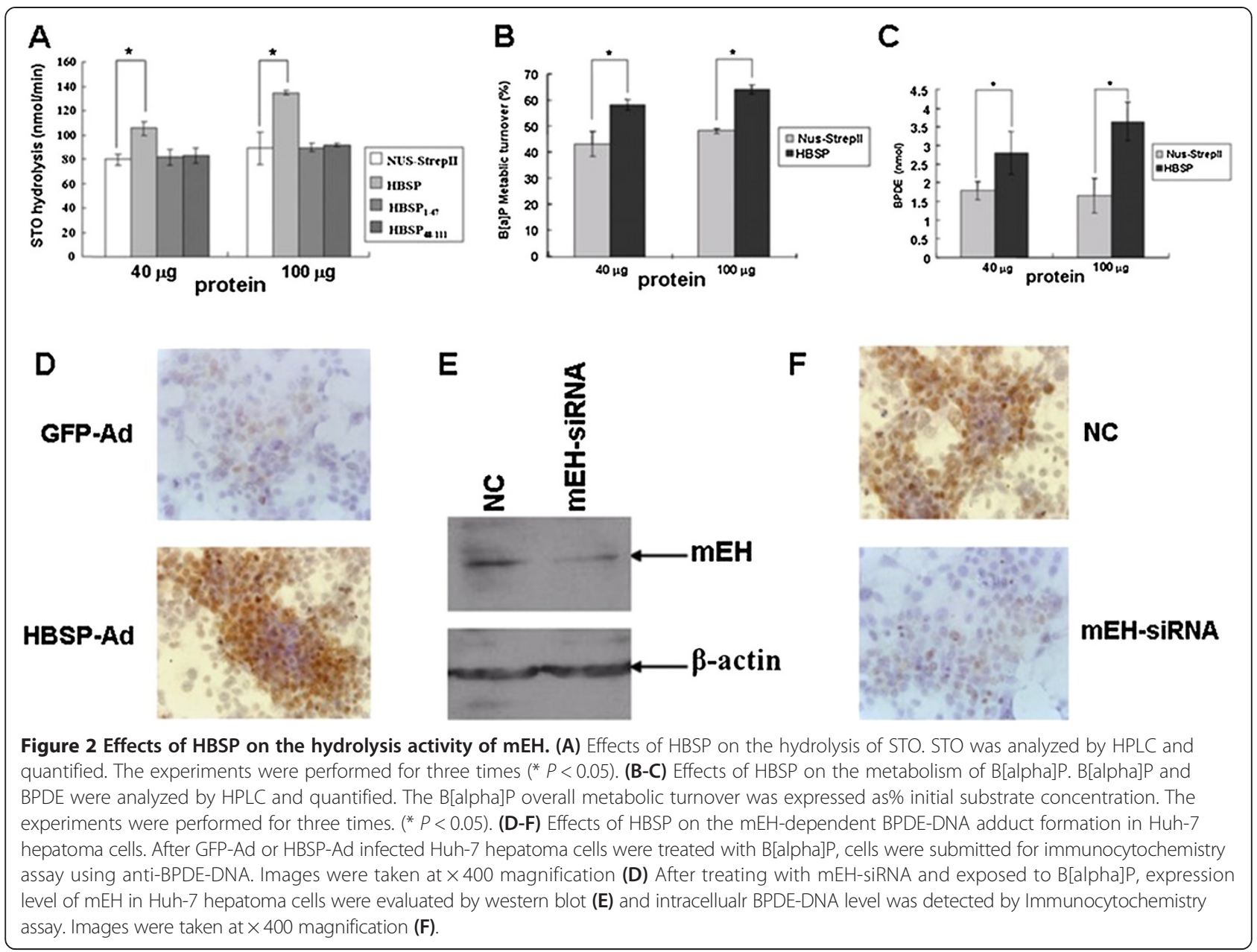

that there was more intense BPDE-DNA staining in the xenografts derived from the Huh-7/HBSP/B[alpha]P as compared to that in the xenografts from Huh-7/GFP/B [alpha]P (Figure 6C). In addition, xenografts derived from the Huh-7/HBSP/B[alpha]P cells were significantly larger and heavier compared to the those from the Huh-7/GFP/ B[alpha]P cells (xenografts volume: $1861 \pm 120 \mathrm{~mm}^{3}$ vs $222 \pm 98 \mathrm{~mm}^{3}$; xenografts weight: $1.69 \pm 0.28 \mathrm{~g}$ vs $0.08 \pm$ $0.04 \mathrm{~g}, \mathrm{P}<0.01$ ) (Figure $6 \mathrm{D}$ and $\mathrm{E}$ ). These data suggest that HBSP enhances tumor development of $\mathrm{B}$ [alpha]Ptreated Huh-7 hepatoma cells, and this enhancement of HBSP is accompanied by the formation of more BPDEDNA adducts in the tumor cells.

\section{Discussion}

Virus-chemical interactions as mechanisms of carcinogenesis have been proposed based on epidemiological investigations. For example, tar-based carcinogens generated from lysol virgin dunching, cigarette smoking, or cooking over burning wood were co-carcinogens for human papillomavirus (HPV) types 16 and 18 in cervical cancer [29-33].
Nitrite inhalants and aluminosilicates were considered as co-carcinogens for human herpes virus type 8 (HHV-8) in oncogenesis of human immunodeficiency virus (HIV)-associated Kaposi's sarcoma (KS) [34,35]. Hepatocarcinogenesis involves a complex interplay of viral, environmental, and host factors. Long incubation period between the time of initial HBV infection and the onset of HCC suggests that HBV plays a role in liver oncogenesis as a cofactor or tumor promoter rather than a direct cause of cancer [36-38]. In fact, the crucial role of hepatocarcinogen diethylnitrosamine in the tumor development of $\mathrm{HBx}$ transgenic mice [39], and the synergistic interactions between HBV and aflatoxins or alcohol in HCC have been well documented $[40,41]$. In the present study, HBV-B [alpha]P interaction in hepatocarcinogenesis was further confirmed and the mechanisms explored.

$\mathrm{B}$ [alpha]P is a major toxicant in diesel exhaust, charcoalbroiled food, industrial waste byproducts, and cigarette smoke $[42,43]$. Administration of $\mathrm{B}[$ alpha]P by different routes has been shown to result in the production of tumors in several species of animals $[44,45]$. The metabolic 
A

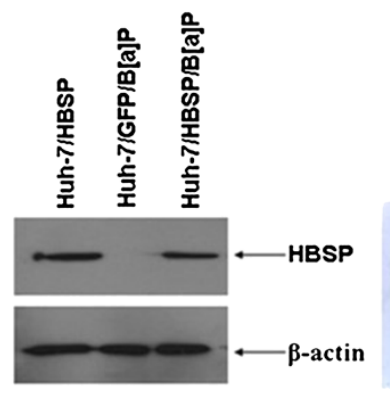

B

Huh-7/HBSP Huh-7/GFP/B[a]P Huh-7/HBSP/B[a]P

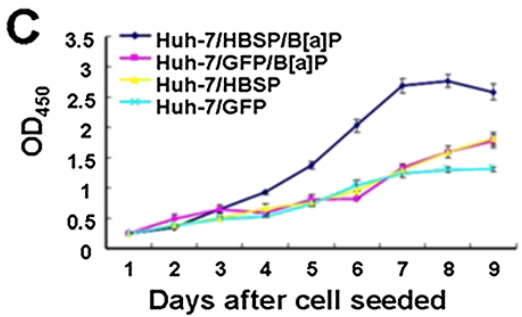

Figure 3 Effects of HBSP on the proliferation of B[alpha]P-treated Huh-7 hepatoma cells. (A) HBSP expression in Huh-7/HBSP/B[alpha]P, Huh-7/GFP/B[alpha]P or Huh-7/HBSP. $30 \mu \mathrm{g}$ of cellular proteins were subjected to 12\% SDS-PAGE, transfered to a PVDF membrane, and probed with anti-mEH. $\beta$-actin served as a loading control. (B) Detection of BPDE-DNA in Huh-7/HBSP/B[alpha]P, Huh-7/GFP/B[alpha]P or Huh-7/HBSP cells. Cells on sterilized glass coverslips were detected for BPDE-DNA by immunocytochemistry assay. Images were taken at $\times 400$ magnification. (C) Cell proliferation of Huh-7/HBSP/B[alpha]P, Huh-7/GFP/B[alpha]P, Huh-7/HBSP or Huh-7/GFP cells. Cells were seeded in 96-well plates at $2 \times 10^{3}$ /well, cell proliferation was determined daily in triplicate for 9 days by BrdU assay. The optical density (OD) was measured at $450 \mathrm{~nm}$ using a microplate reader. The analyses were repeated three times, and the results were expressed as mean \pm SD. activation pathway of $\mathrm{B}[\mathrm{alpha}] \mathrm{P}$ involves three sequential enzymatically catalyzed reactions including monooxygenation by cytochrome P450 (CYP) enzymes, hydration by $\mathrm{mEH}$ and a second CYP-catalyzed oxidation to generate a carcinotoxic ultimate product, BPDE [46], which is capable of binding covalently to DNA in the living cells to form adducts [16]. In the present study, it was demonstrated that HBSP generated by a $2.2 \mathrm{~kb}$ singly-spliced HBV pre-genomic RNA could specifically bind to the Cterminal region (amino acid residues 353-455) of $\mathrm{mEH}$, and resulted in an increase in the hydrolysis activity of $\mathrm{mEH}$, as demonstrated by hydrolysis assay using STO, an artificial substrate. In addition, it was also demonstrated that HBSP could accelerate B[alpha]P metabolism in mouse liver microsomes leading to an increased amount of BPDE-DNA adducts. In Huh-7 hepatoma cells, expression of HBSP resulted in an increased formation of BPDE-DNA adducts, and this enhancement effect could be blocked when $\mathrm{mEH}$ was knocked down by siRNA, implicating an indispensable mechanistic role that $\mathrm{mEH}$ plays in the enhancement. HBSP begins at the HBV polymerase start codon and contains the first 47 amino acids residues of polymerase (Met1-Asn47, $\mathrm{HBSP}_{1-47}$ ), followed by the 64 amino acids residues (Glu48-Tyr111, HBSP $\left._{48-111}\right)$ resulting from a frameshift event $[10,21]$. More importantly, nucleotide sequence alignment comparison 
A

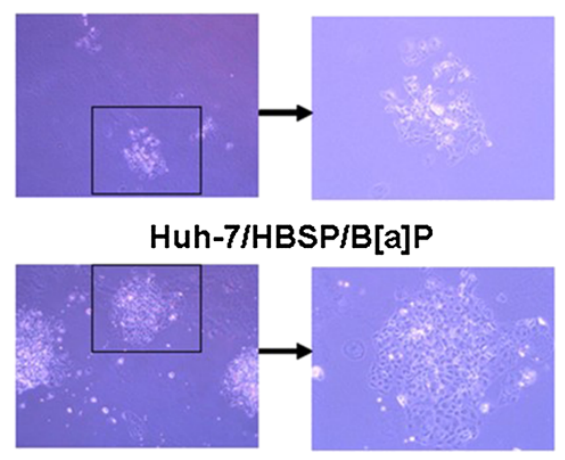

B

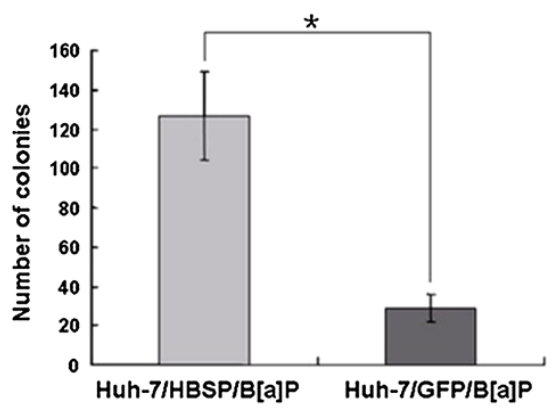

Figure 5 Effects of HBSP on anchorage-independent growth of B[alpha]P-treated Huh-7 hepatoma cells in soft agar. (A) Huh-7/HBSP/ B[alpha]P or Huh-7/GFP/ B[alpha]P cells grown in soft agar 14 days after plating. Images on left were taken at $\times 40$ magnification. Images on the right were $\times 100$ magnified and images of the boxed sections depicted on the left. (B) The number of colonies grown in the soft agar. $(*<0.05)$.

among the eight (A-H) known genotypes of HBV showed that the sequence following the $5^{\prime}$-splice site at nucleotide 2447 and that following the 3 '-splice site at nucleotide 489 are highly conserved (data not shown), suggesting that generation and function of HBSP are
HBV genotype-independent. In this study, it was shown that while HBSP-mEH complex formation was mediated by $\mathrm{N}$ terminal 47 amino acid residues of HBSP, the enhancement of $\mathrm{mEH}$ activities requires the intact HBSP molecule.

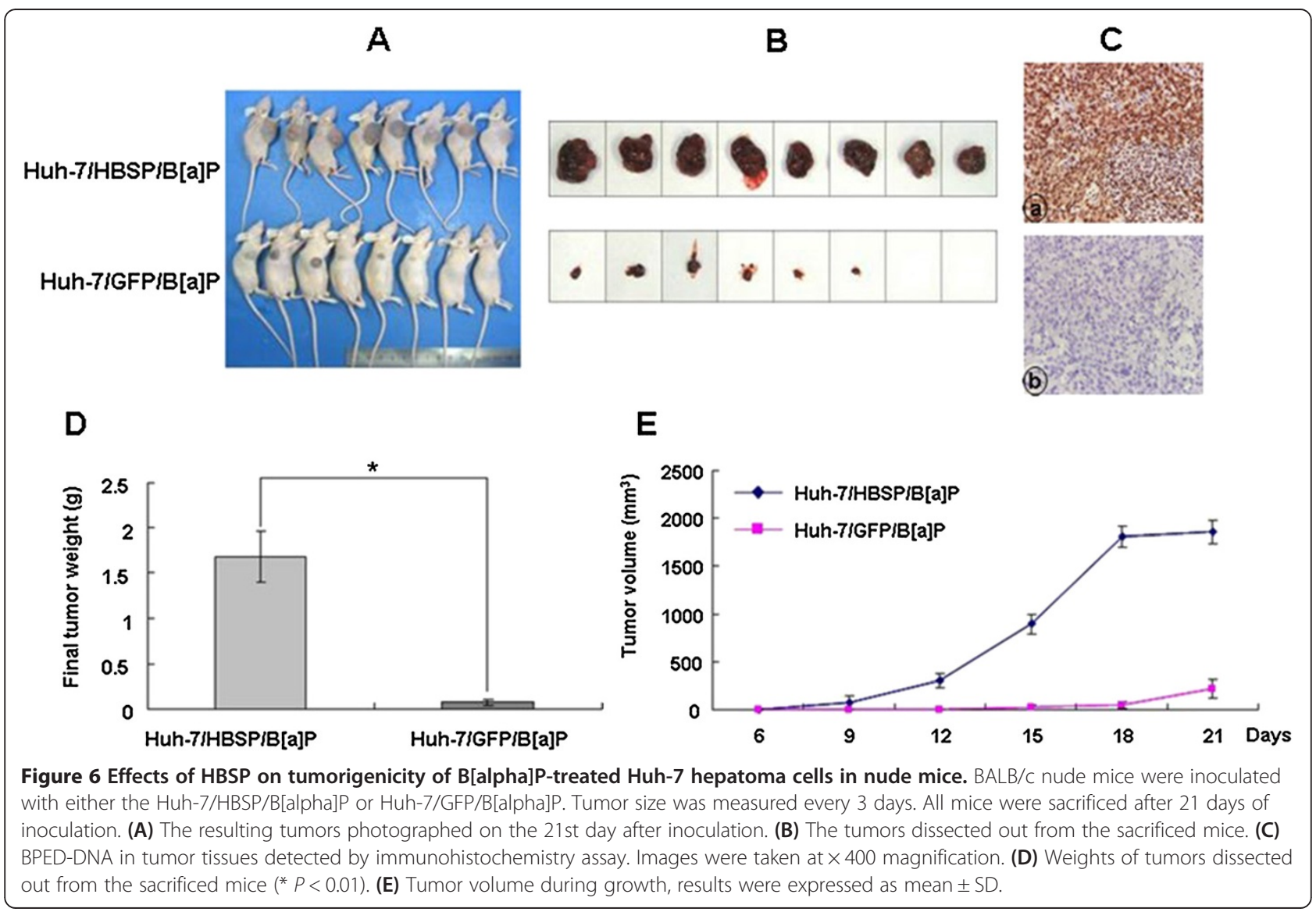


$\mathrm{B}$ [alpha]P accelerates cell cycle progression from G1 phase to $\mathrm{S}$ phase and induces cell proliferation in human embryo lung fibroblasts (HELF). This effect was mediated by c-Jun activation by PI-3 K/Atk/ERK signaling pathway with the up-regulation of expression of cyclin D1, E2F1 and pRb [47]. Moreover, BPDE has been documented to promote cell transformation and tumorigenesis through the induction of cyclin D1 via the PI-3 K /Akt/MAPK and p70s6k-dependent pathway [48]. Recently, interaction of HBSP with CTSB was found to promote hepatoma cell motility and invasion, the mechanisms involve the secretion and activation of proteolytic enzymes, increased tumor-induced angiogenesis, and activation of the MAPK/Akt signaling [49]. In the present study, it was demonstrated that HBSP could enhance the cell proliferation, accelerate the G1/S transition, and promote cell transformation and tumorigenesis of $\mathrm{B}[$ alpha]Ptreated Huh-7 hepatoma cells. These results suggest the co-carcinogenesis of HBSP and B[alpha]P in HCC, and shed a new light for potential therapeutic intervention to prevent hepatocarcinogenesis in the hepatitis B patients with high $\mathrm{B}[\mathrm{alpha}] \mathrm{P}$ exposure by $\mathrm{mEH}$ and/or HBSP suppression treatment.

\section{Conclusions}

In summary, the results of this study demonstrate that HBSP promotes carcinogenic effects of $B[$ alpha]P through enhancing the hydrolysis activities of $\mathrm{mEH}$, thereby accelerating the conversion of $\mathrm{B}$ [alpha]P to BPDE and increasing the formation of BPDE-DNA adducts while the physiological significance of HBSP remains to be verified by comparing full-length HBV (capable of replication and expression of all the viral proteins at appropriate ratios) with a mutant incapable of splicing or expression of the intact HBSP. These findings not only broaden the knowledge of virus-chemical interactions in co-carcinogenesis of HCC, may also lead to the further study of chemoprevention of $\mathrm{HBV}$-associated $\mathrm{HCC}$.

\section{Competing interests}

All authors declare that they have no competing interests.

\section{Authors' contributions}

JYC, WNC, BYJ and WSL performed the experiments, interpreted the results. YLW and LLL contributed to the scientific discussion. JYC drafted the manuscript. XL was the project leader. All authors read and approved the final manuscript.

\section{Acknowledgements}

This work was supported by grants from National Nature Science Foundation of China (30970163), State Key Project Specialized for Infectious Diseases (2012ZX10002008-007 and 2013ZX10004216-005-002), Key Program of Scientific Research (09ZD004) and Program for Innovative Research Team in Science and Technology (FMU-RT001) from Fujian Medical University.

\section{Author details}

'Key Laboratory of Ministry of Education for Gastrointestinal Cancer, Research Center of Molecular Medicine, Fujian Medical University, Fuzhou, Fujian 350004, P.R. China. ${ }^{2}$ Fujian Academy of Medical Sciences, Fuzhou, Fujian
350001, P.R. China. ${ }^{3}$ Key Laboratory of Tumor Microbiology, Department of Medical Microbiology, Fujian Medical University, Fuzhou, Fujian 350004, P.R. China.

Received: 6 August 2013 Accepted: 16 April 2014

Published: 23 April 2014

\section{References}

1. Parkin DM, Bray F, Ferlay J, Pisani P: Estimating the world cancer burden: GLOBOCAN 2000. Int J Cancer 2001, 94:153-156.

2. Thorgeirsson SS, Grisham JW: Molecular pathogenesis of human hepatocellular carcinoma. Nat Genet 2002, 31:339-346.

3. Chen SY, Wang LY, Lunn RM, Tsai WY, Lee PH, Lee CS, Ahsan H, Zhang YJ, Chen CJ, Santella RM: Polycyclic aromatic hydrocarbon-DNA adducts in liver tissues of hepatocellular carcinoma patients and controls. Int J Cancer 2002, 99:14-21.

4. Wu HC, Wang $Q$, Wang LW, Yang HI, Ahsan H, Tsai WY, Wang LY, Chen SY, Chen CJ, Santella RM: Polycyclic aromatic hydrocarbon- and aflatoxin-albumin adducts, hepatitis B virus infection and hepatocellular carcinoma in Taiwan. Cancer Lett 2007, 252:104-114.

5. Ganem D, Varmus HE: The molecular biology of the hepatitis B viruses. Annu Rev Biochem 1987, 56:651-693.

6. Feitelson MA, Duan LX: Hepatitis $B$ virus $X$ antigen in the pathogenesis of chronic infections and the development of hepatocellular carcinoma. Am J Pathol 1997, 150:1141-1157.

7. Su Q, Schröder CH, Hofmann WJ, Otto G, Pichlmayr R, Bannasch P: Expression of hepatitis $B$ virus $X$ protein in $\mathrm{HBV}$ infected human livers and hepatocellular carcinomas. Hepatology 1998, 27:1109-1120.

8. Wang HC, Huang W, Lai MD, Su IJ: Hepatitis B virus pre-S mutants, endoplasmic reticulum stress and hepatocarcinogenesis. Cancer Sci 2006, 97:683-688.

9. Günther S, Sommer G, Iwanska A, Will H: Heterogeneity and common features of defective hepatitis B virus genomes derived from spliced pregenomic RNA. Virology 1997, 238:363-371.

10. Soussan P, Garreau F, Zylberberg H, Ferray C, Brechot C, Kremsdorf D: In vivo expression of a new hepatitis $B$ virus protein encoded by a spliced RNA. J Clin Invest 2000, 105:55-60.

11. Rosmorduc O, Petit MA, Pol S, Capel F, Bortolotti F, Berthelot P, Brechot C, Kremsdorf D: In vivo and in vitro expression of defective hepatitis $B$ virus particles generated by spliced hepatitis B virus RNA. Hepatology 1995, 22:10-19.

12. Soussan P, Tuveri R, Nalpas B, Garreau F, Zavala F, Masson A, Pol S, Brechot C, Kremsdorf D: The expression of hepatitis B spliced protein (HBSP) encoded by a spliced hepatitis $B$ virus RNA is associated with viral replication and liver fibrosis. J Hepatol 2003, 38:343-348.

13. Mancini-Bourgine M, Bayard F, Soussan P, Deng Q, Lone YC, Kremsdorf D, Michel ML: Hepatitis B virus splice-generated protein induces T-cell responses in HLA-transgenic mice and hepatitis B virus-infected patients. J Virol 2007, 81:4963-4972.

14. Kleiner HE, Vulimiri SV, Hatten WB, Reed MJ, Nebert DW, Jefcoate CR, DiGiovanni J: Role of cytochrome p4501 family members in the metabolic activation of polycyclic aromatic hydrocarbons in mouse epidermis. Chem Res Toxicol 2004, 17:1667-1674.

15. Baird WM, Hooven LA, Mahadevan B: Carcinogenic polycyclic aromatic hydrocarbon-DNA adducts and mechanism of action. Environ $\mathrm{Mol}$ Mutagen 2005, 45:106-114.

16. Xue W, Warshawsky D: Metabolic activation of polycyclic and heterocyclic aromatic hydrocarbons and DNA damage: A review. Toxicol Appl Pharmacol 2005, 206:73-93.

17. Rodriguez LV, Dunsford HA, Steinberg M, Chaloupka KK, Zhu L, Safe S, Womack JE, Goldstein LS: Carcinogenicity of benzo[a]pyrene and manufactural gas plant residues in infant mice. Carcinogenesis 1997 18:127-135.

18. Gelboin HV: Benzo[alpha]pyrene metabolism, activation and carcinogenesis: role and regulation of mixed-function oxidases and related enzymes. Physiol Rev 1980, 60:1107-1166.

19. Kim JY, Chung JY, Park JE, Lee SG, Kim YJ, Cha MS, Han MS, Lee HJ, Yoo YH, Kim JM: Benzo[alpha]pyrene Induces Apoptosis in RL95-2 Human Endometrial Cancer Cells by Cytochrome P450 1A1 Activation. Endocrinology 2007, 148:5112-5122. 
20. Miyata M, Kudo G, Lee YH, Yang TJ, Gelboin HV, Fernandez-Salguero P, Kimura S, Gonzalez FJ: Targeted disruption of the microsomal epoxide hydrolase gene. microsomal epoxide hydrolase is required for the carcinogenic activity of 7,12-dimethylbenz[alpha]anthracene. J Biol Chem 1999, 274:23963-23968.

21. Chen JY, Chen WN, Liu LL, Lin WS, Jiao BY, Wu YL, Lin JY, Lin X: Hepatitis B Spliced Protein (HBSP) Generated by a Spliced Hepatitis B Virus RNA Participates in Abnormality of Fibrin Formation and Functions by Binding to Fibrinogen gamma Chain. J Med Virol 2010, 82:2019-2026.

22. Cottrell L, Golding BT, Munter T, Watson WP: In vitro metabolism of chloroprene: Species differences, epoxide stereochemistry and a de-chlorination pathway. Chem Res Toxicol 2001, 14:1552-1562.

23. Berry DL, Bracken WR, Slaga TJ, Wilson NM, Butty SG, Juchau MR: Benzo [alpha]pyrene metabolism in mouse epidermis analysis by high pressure liquid chromatography and DNA binding. Chem Biol Interact 1977, 18:129-142.

24. Zhong LP, Pan HY, Zhou XJ, Ye DX, Zhang L, Yang X, Chen WT, Zhang ZY: Characteristics of a cancerous cell line, HIOEC-B[alpha]P-96, induced by benzo[alpha]pyrene from human immortalized oral epithelial cell line. Arch Oral Biol 2008, 53:443-452.

25. Macpherson I, Montagnier L: Agar Suspension Culture for the Selective Assay of Cells Transformed by Polyoma Virus. Virology 1964, 23:291-294.

26. Kim YS, Burns AL, Goldsmith PK, Heppner C, Park SY, Chandrasekharappa SC, Collins FS, Spiegel AM, Marx SJ: Stable overexpression of MEN1 suppresses tumorigenicity of RAS. Oncogene 1999, 18:5936-5942.

27. Gao A, Liu BC, Shit XL, Huang CS, Jia XW, You BR, Ye M, Shen FH, Du HJ: Vitamin $C$ inhibits benzo[alpha]pyrene-induced cell cycle changes partly via cyclin D1/E2F pathway in human embryo lung fibroblasts. Biomed Environ Sci 2006, 19:239-244.

28. Jia X, Liu B, Shi X, Gao A, You B, Ye M, Shen F, Du H: Inhibition of Benzo [alpha]pyrene-induced cell cycle progression by all-trans retinoic acid partly through cyclin D1/E2F-1 pathway in human embryo lung fibroblasts. Cell Biol Int 2006, 30:183-189.

29. Smith FR: Etiologic factors in carcinoma of the cervix. Am J Obstet Gynecol 1931, 21:18-25.

30. Rotkin ID: Epidemiology of cancer of the cervix. 3. Sexual characteristics of a cervical cancer population. Am J Public Health Nations Health 1967, 57:815-829.

31. Ferrera A, Velema JP, Figueroa M, Bulnes R, Toro LA, Claros JM, De Barahona O, Melchers WJ: Co-factors related to the causal relationship between human papillomavirus and invasive cervical cancer in Honduras. Int J Epidemiol 2000, 29:817-825.

32. Hildesheim A, Herrero R, Castle PE, Wacholder S, Bratti MC, Sherman ME, Lorincz AT, Burk RD, Morales J, Rodriguez AC, Helgesen K, Alfaro M, Hutchinson M, Balmaceda I, Greenberg M, Schiffman M: HPV co-factors related to the development of cervical cancer: results from a population-based study in Costa Rica. Br J Cancer 2001, 84:1219-1226.

33. Castle PE, Wacholder S, Lorincz AT, Scott DR, Sherman ME, Glass AG, Rush BB, Schussler JE, Schiffman M: A prospective study of high-grade cervical neoplasia risk among human papillomavirus-infected women. J Natl Cancer Inst 2002, 94:1406-1414.

34. Haverkos HW: Is Kaposi's sarcoma caused by new herpesvirus? Biomed Pharmacother 1996, 50:318-319.

35. Ziegler J, Simonart T, Snoeck R: Kaposi's sarcoma, oncogenic viruses, and iron. J Clin Virol 2001, 20:127-130.

36. Dunsford HA, Sell S, Chisari FV: Hepatocarcinogenesis Due to Chronic Liver Cell Injury in Hepatitis B Virus Transgenic Mice. Cancer Res 1990, 50:3400-3407

37. Madden CR, Slagle BL: Stimulation of cellular proliferation by hepatitis B virus X protein. Dis Markers 2001, 17:153-157.

38. Bréchot C: Pathogenesis of hepatitis B virus-related hepatocellular carcinoma: old and new paradigms. Gastroenterology 2004, 127:S56-S61.

39. Madden CR, Finegold MJ, Slagle BL: Altered DNA mutation spectrum in aflatoxin b1-treated transgenic mice that express the hepatitis $B$ virus x protein. J Virol 2002, 76:11770-11774.

40. Ming L, Thorgeirsson SS, Gail MH, Lu P, Harris CC, Wang N, Shao Y, Wu Z, Liu G, Wang X, Sun Z: Dominant role of hepatitis B virus and co-factor role of aflatoxin in hepatocarcinogenesis in Qidong, China. Hepatology 2002, 36:1214-1220

41. Hassan MM, Hwang LY, Hatten CJ, Swaim M, Li D, Abbruzzese JL, Beasley P Patt YZ: Risk factors for hepatocellular carcinoma: synergism of alcohol with viral hepatitis and diabetes mellitus. Hepatology 2002, 36:1206-1213.
42. Hattemer-Frey HA, Travis CC: Benzo[alpha]pyrene: environmental partitioning and human exposure. Toxicol Ind Health 1991, 7:141-157.

43. Knize MG, Salmon CP, Pais P, Felton JS: Food heating and the formation of heterocyclic aromatic amine and polycyclic aromatic hydrocarbon mutagens/carcinogens. Adv Exp Med Biol 1999, 459:179-193.

44. Shubik P: The growth potentialities of induced skin tumors in mice. The effects of different methods of chemical carcinogenesis. Cancer Res 1950, 10:713-717.

45. Rubin H: Synergistic mechanisms in carcinogenesis by polycyclic aromatic hydrocarbons and by tobacco smoker: a bio-historical perspective with updates. Carcinogenesis 2001, 22:1903-1930.

46. Beresford AP: CYP1A1: friend or foe? Drug Metab Rev 1993, 25:503-517.

47. Jiao S, Liu B, Gao A, Ye M, Jia X, Zhang F, Liu H, Shi X, Huang C: Benzo [alpha]pyrene-caused increased G1-S transition requires the activation of c-Jun through p53-dependent PI-3 K/Akt/ERK pathway in human embryo lung fibroblasts. Toxicol Lett 2008, 178:167-175.

48. Gao A, Liu B, Shi X, Jia X, Ye M, Jiao S, You B, Huang C: Phosphatidylinositol-3 kinase/Akt/p70S6K/AP-1 signaling pathway mediated benzo[alpha]pyrene-induced cell cycle alternation via cell cycle regulatory proteins in human embryo lung fibroblasts. Toxicol Lett 2007, 170:30-41.

49. Chen WN, Chen JY, Jiao BY, Lin WS, Wu YL, Liu LL, Lin X: Interaction of Hepatitis B spliced protein (HBSP) with cathepsin B promotes hepatoma cell migration and invasion. J Virol 2012, 86:13533-13541.

doi:10.1186/1471-2407-14-282

Cite this article as: Chen et al:: Hepatitis B spliced protein (HBSP) promotes the carcinogenic effects of benzo [alpha] pyrene by interacting with microsomal epoxide hydrolase and enhancing its hydrolysis activity. BMC Cancer 2014 14:282

\section{Submit your next manuscript to BioMed Central and take full advantage of:}

- Convenient online submission

- Thorough peer review

- No space constraints or color figure charges

- Immediate publication on acceptance

- Inclusion in PubMed, CAS, Scopus and Google Scholar

- Research which is freely available for redistribution 